\title{
Modeling Char Surface Area Evolution during Coal Pyrolysis: Evolving Characteristics with Coal Rank
}

\author{
He Yang ${ }^{1}$, Yahui Yang ${ }^{2}$, Sarma Pisupati ${ }^{3}$, Lijun Jin ${ }^{1}$, Yang $\mathrm{Li}^{1}$, and Haoquan $\mathrm{Hu}^{1}$ \\ ${ }^{1}$ Dalian University of Technology \\ ${ }^{2}$ Dalian University of Technology School of Chemical Engineering \\ ${ }^{3}$ Pennsylvania State University
}

October 27, 2020

\begin{abstract}
Crosslinked metaplast influences char $\mathrm{N}_{2}$ adsorption specific surface area $\left(S_{\mathrm{N} 2}\right)$, and the influence changes with coal rank significantly. When crosslinked metaplast is adequate, planar polycyclic aromatic structures overlap tightly and $S_{\mathrm{N} 2}$ is small. When crosslinked metaplast content is small, $S_{\mathrm{N} 2}$ in crosslinked metaplast is larger than that in the coal matrix and takes a considerable proportion of total char surface area. Two exponents, $k_{\text {mat order }}$ and $k_{\text {crlmet order }}$, representing order degrees of planar polycyclic aromatic structure arrangement in coal matrix and crosslinked metaplast, respectively, were introduced in the previous model for calculating the change of char surface area during coal pyrolysis. The previous model was extended to include predicting $S_{\mathrm{N} 2}$ of subbituminous and high-volatile bituminous coals, and was validated with 5 subbituminous coals, and 2 bituminous coals. The change of $S_{\mathrm{N} 2}$ with coal ranks and the transition characteristics between coal ranks can be predicted.
\end{abstract}

\section{Hosted file}

Main Document Modeling Char Surface Area Evolution during Coal Pyrolysis Evolving Characteristics with available at https://authorea.com/users/370684/articles/489268-modeling-char-surface-areaevolution-during-coal-pyrolysis-evolving-characteristics-with-coal-rank 